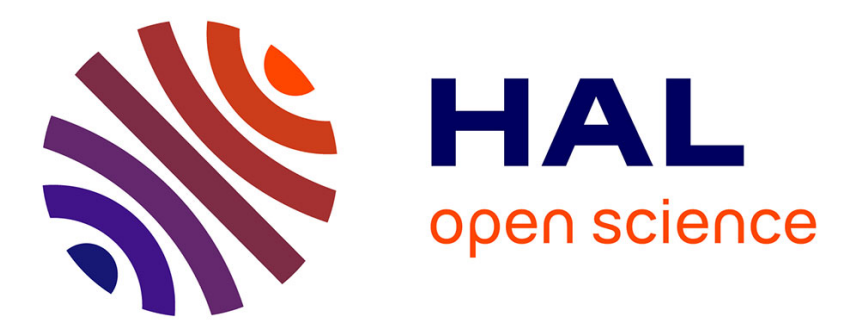

\title{
GMI low frequency noise characterization versus wire diameters
}

A. Esper, E. Portalier, Basile Dufay, C. Dolabdjian, S. Corodeanu, H. Chiriac

\section{To cite this version:}

A. Esper, E. Portalier, Basile Dufay, C. Dolabdjian, S. Corodeanu, et al.. GMI low frequency noise characterization versus wire diameters. 2017 IEEE SENSORS , Oct 2017, Glasgow, United Kingdom. 10.1109/ICSENS.2017.8234270 . hal-01708024

\section{HAL Id: hal-01708024 \\ https://hal.science/hal-01708024}

Submitted on 15 Jun 2018

HAL is a multi-disciplinary open access archive for the deposit and dissemination of scientific research documents, whether they are published or not. The documents may come from teaching and research institutions in France or abroad, or from public or private research centers.
L'archive ouverte pluridisciplinaire $\mathbf{H A L}$, est destinée au dépôt et à la diffusion de documents scientifiques de niveau recherche, publiés ou non, émanant des établissements d'enseignement et de recherche français ou étrangers, des laboratoires publics ou privés. 


\title{
GMI Low Frequency Noise Characterization Versus Wire Diameters
}

\author{
A. Esper ${ }^{1}$, E. Portalier ${ }^{1}$, B. Dufay ${ }^{1}$, C. Dolabdjian ${ }^{1}$, S. Corodeanu ${ }^{2}$, H. Chiriac ${ }^{2}$ \\ ${ }^{1}$ Groupe de Recherche en Informatique, Image, Automatique et Instrumentation \\ Normandie Univ, UNICAEN, ENSICAEN, CNRS, GREYC \\ 14000 Caen, France \\ ${ }^{2}$ National Institute of Research and Development for Technical Physics \\ Ministry of Education and Scientific Research, National Authority for Scientific Research and Innovation, NIRDTP \\ Iasi RO-700050, Romania \\ alexandre.esper@unicaen.fr
}

\begin{abstract}
Equivalent magnetic noise levels at $1 \mathrm{~Hz}$ of three GMI samples have been experimentally determined for different excitation conditions related to both dc current and ac excitation amplitude. These three wires or cylindrical-shaped samples are from the exact same alloy composition and obtained from the same fabrication process. The only difference is their diameter which are $80 \mu \mathrm{m}, 100 \mu \mathrm{m}$ and $120 \mu \mathrm{m}$, since this parameter has been identified as an important factor involved in GMI low frequency noise level. Indeed, from the recently proposed model, briefly reminded here, the equivalent magnetic noise level should decrease with the square of the wire diameter. These low frequency equivalent magnetic noise level measurements have been conducted with coherence measurements showing that the main noise source responsible of this noise level is the intrinsic noise of the GMI sensor. Obtained results have then been compared to the expected noise level from the theoretical model, showing a relative good agreement, validating the behavior regarding wire diameter.
\end{abstract}

Keywords—Giant MagnetoImpedance; noise ; magnetometer.

\section{INTRODUCTION}

Materials exhibiting a Giant Magneto-Impedance (GMI) effect have been identified as good candidates for high sensitivity magnetometry thanks to their huge impedance variation with the external applied magnetic field, at room temperature $[1,2]$. This effect relies on the penetration depth variation of the high frequency ac excitation current in the material while exposed to an external magnetic field applied in easy axis. The field sensitivity could further be improved when using an off-diagonal configuration [3], where the GMI material is strongly coupled with a pick-up coil.

An important characteristic for designing high sensitivity magnetometers is the equivalent magnetic noise level, since it ultimately limits the lowest magnetic field which could be detected by the sensor. In the case of soft ferromagnetic amorphous wires, it has been recently proposed that the low frequency equivalent magnetic noise level, which exhibits an $1 / f$ behavior, is dominated by the intrinsic noise of the sensing element itself [4]. The intrinsic origin of the noise has been experimentally proved thanks to cross correlation measurements, for optimal excitation conditions, for which the resulting noise level at $1 \mathrm{~Hz}$ is minimal. At the same time, a theoretical model has been proposed to predict this low frequency noise level based on the low frequency fluctuations of the magnetization direction [5]. The resulting expression of the theoretical equivalent magnetic power spectral density (expressed in $\mathrm{T}^{2} / \mathrm{Hz}$ ) is

$$
b_{n}^{2}(f) \approx \frac{6 \mu_{0} k_{B} T}{\pi^{2} d^{2} L}\left(\frac{H_{k}}{M_{s}}\right)^{2} \frac{\chi^{\prime \prime}(f)}{f}
$$

where $H_{k}$ is the anisotropy field, $\chi^{\prime \prime}(f)$ is the imaginary parts of the magnetic transverse susceptibility, $M_{S}$ is the magnetization saturation, $k_{B}$ is the Boltzmann constant, $T$ the temperature, $\mu_{0}$ the vacuum permeability, and $L$ and $d$ are the length and the diameter of the wire, respectively. This model was successfully validated for several GMI samples from different materials [6]. In this paper, we proposed to enhance this validation by investigating the impact of the wire diameter, $d$, as (1) predict that the noise level should increase inversely to the square of $d$.

The paper is organized as follows. Section II describes the experimental conditions. Both sample characteristics and involved measurements setups are described. Section III is dedicated to obtained results and discussion. We conclude in section IV.

\section{MATERIAL AND EXPERIMENTAL METHODS}

\section{A. GMI samples}

1) Fabrication process and geometric properties:

Our study was conducted on three GMI samples. All of these are soft ferromagnetic amorphous wires with the same nominal composition $\mathrm{Co}_{68.15} \mathrm{Fe}_{4.35} \mathrm{Si}_{12.5} \mathrm{~B}_{15}$ and diameters of $80 \mu \mathrm{m}$ (sample R80), $100 \mu \mathrm{m}$ (sample R100) and $120 \mu \mathrm{m}$ (sample R120). They were prepared at the National Institute of Research and Development for Technical Physics, using the in rotating water melt spinning method. This fabrication process consists in melting few grams of alloy inside a special quartz crucible, under argon atmosphere, using a high-frequency inductor. This melt is then ejected through a small circular hole in a layer of water, which is contained in a rotating disk with special profile, by applying an argon overpressure in the crucible [7]. At the contact with the water, the stream of molten alloy is quickly 
cooled with cooling rate as fast as $10^{6} \mathrm{~K} / \mathrm{s}$, and solidifies as an amorphous wire. The diameter of the wire is mainly given by the hole diameter, which needs to be correlated with argon overpressure and peripheral speed of the cooling fluid in order to obtain long cylindrical samples. Due to the very specific fabrication process, the amorphous wires have a remarkable symmetry not only geometrically, but also in terms of induced tensions and magnetic domain structure [8-10].

Final sensors are constituted of a $24 \mathrm{~mm}$ long wire, for each of the three diameters, associated with a pickup coil of 450 turns.

\section{2) Magnetic properties}

As to compute the expected low frequency noise level given by (1), some magnetic properties of the samples have to be evaluated. First of all, the saturation magnetization, $M_{S}$, was determined using a differential fluxmeter method [11]. Fig. 1 shows the obtain hysteresis loop for the three samples recorded at a frequency of $50 \mathrm{~Hz}$ and a magnetic field applied in the longitudinal direction. All samples show similar saturation magnetization value of $540 \mathrm{kA} / \mathrm{m}$, as usually expected for such material.

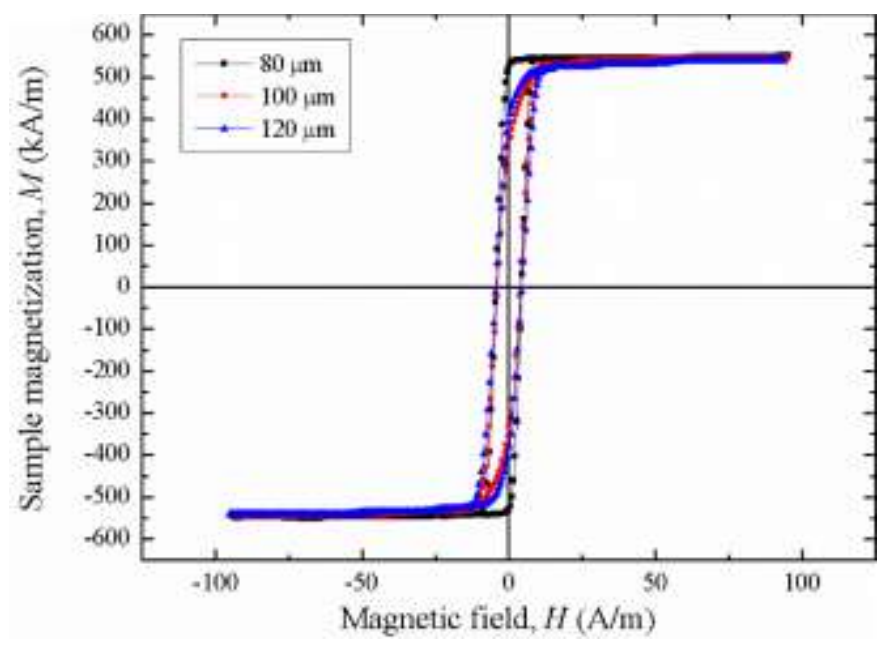

Fig. 1. Hysteresis loop of the three samples, measured at $50 \mathrm{~Hz}$ for a magnetic field applied along the longitudinal direction.

Furthermore, the hysteresis loop shows almost the same coercivity, of $3 \mathrm{~A} / \mathrm{m}$, for all analyzed samples. The retentivity value was higher for the thinner sample $(R 80)$, with a value of $517 \mathrm{kA} / \mathrm{m}$, and lower for the thicker ones (R120), around $358 \mathrm{kA} / \mathrm{m}$. These differences probably appear due to different cooling rates, which should be higher in thinner samples, as well as to the changes in the stress distribution inside the wire. Indeed, this later influences the domain structure by increasing the area with circular magnetization for samples with higher diameter.

GMI response, at a frequency of $1 \mathrm{MHz}$, of each sample was also evaluated, exhibiting classical two-peaks shape, considering an excitation current amplitude low enough to keep the sample in the linear regime. GMI response allows to determine the anisotropy field, $H_{k}$, which corresponds, in the quasi-static regime, to the field position of the maximum impedance [3]. Values of $63.1 \mathrm{~A} / \mathrm{m}, 24.2 \mathrm{~A} / \mathrm{m}$, and $46 \mathrm{~A} / \mathrm{m}$ were obtained for sample $R 80, R 100$ and $R 120$, respectively. Finally, the imaginary part of magnetic transverse permeability, $\chi^{\prime \prime}(f)$, was evaluated from the measurement of the real part of the impedance as a function of the excitation frequency as exposed in $[4,6,12]$. This was done for several excitation parameters, (involving both ac and dc excitation current amplitude) according to those used during noise measurement as detailed below.

\section{B. Noise measurements}

Each of the three GMI sensors was then operated in a classical electronic conditioning circuitry involving (1) a $1 \mathrm{MHz}$ sine wave current source providing the excitation current flowing through the wire and (2) a demodulation stage based on a classical peak-detector which retrieves the envelop of the voltage induced at the end of the pick-up coil [13].

Studying the intrinsic low frequency noise behavior of GMI samples regarding diameter value is only relevant if the dominant noise source is the intrinsic noise of the sensor, and not a noise source induced by the electronic conditioning circuitry. To insure this, each noise measurement was conducted alongside with coherence measurements using two similar GMI sensors, demodulation stages and a unique current source as excitation stage. Fig. 2 shows the circuit diagram of this setup where the measuring chain separation could occur before (position B) of after (position A) the sensing element thanks to the switch selector. The principle of coherence spectral measurement lies in the fact that the noise of a single signal is measured through two different noise channels giving the ratio of common noise of the channels to total noise. In other words, it allows one to establish if two signals arise from a common origin or from different one.

Then, output signals, $V_{s 1}$ and $V_{s 2}$, from both channels are considered perfectly correlated (in other words, they possess the same origin) at the frequency, $f$, if correlation value $\gamma_{V s 1 V s}^{2}(f)=1$. On the contrary, if $\gamma_{V s 1 V s 2}^{2}(f)=0$, they are totally uncorrelated. In our case, the dominant noise source is the intrinsic noise of the sensor if the two following conditions are respected:

- $\gamma^{2} V_{s I V s}(f) \rightarrow 1$ when the measuring chain separation is placed after the sample (switch selector in A position) and,

- $\gamma_{V s 1 V s 2}^{2}(f) \rightarrow 0$ when the measuring chain separation is placed before the sample (switch selector in position B).

We should note that all noise measurements were done in a 6 layers GREYC magnetic shielded room as to neglect external surrounding noise.

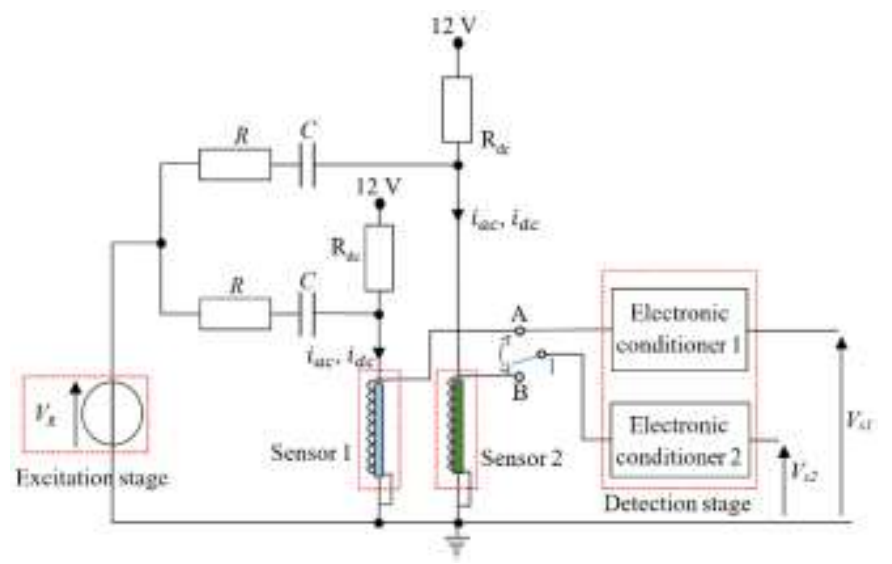

Fig. 2. Circuit diagram used for cross correlation measurements. 


\section{RESULTS AND DISCUSSION}

Fig. 3 shows an example of a measured equivalent magnetic noise spectral density of the sample $R 100$, for $I_{d c}=40 \mathrm{~mA}$ and $I_{a c}=36 \mathrm{~mA}$. It shows a white noise level of $1.4 \mathrm{pT} / \sqrt{\mathrm{Hz}}$, and a $1 / f$ excess noise at low frequency leading to a noise level of $14 \mathrm{pT} / \sqrt{ } \mathrm{Hz}$ at $1 \mathrm{~Hz}$.

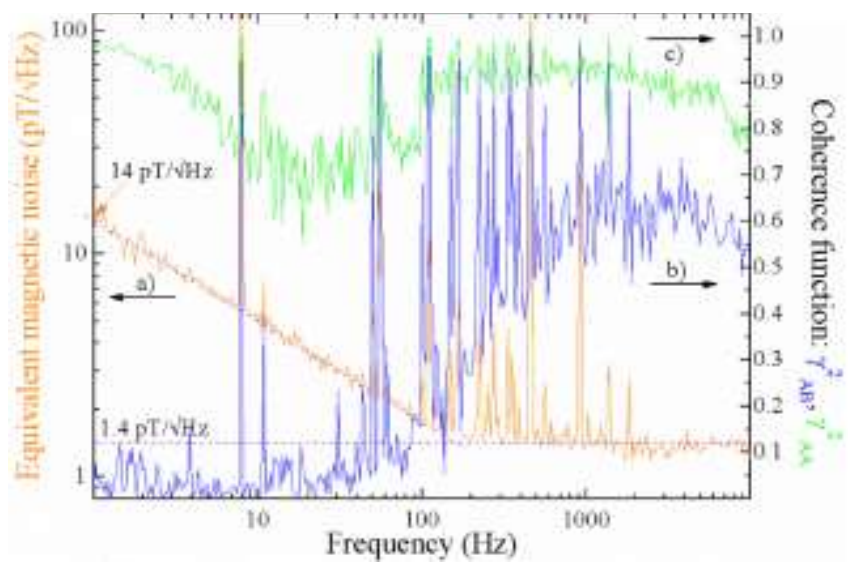

Fig. 3. (a) Equivalent magnetic noise spectral density, and corresponding coherence values when the switch selector is (b) connected to B and (c) connected to A, for the sample R100 with excitation parameters of $I_{a c}=36 \mathrm{~mA}_{\mathrm{rms}}$ at $1 \mathrm{MHz}$ and $I_{d c}=40 \mathrm{~mA}$.

Correlation values at low frequency obtained for a measuring chain separation occurring before and after the sensing element meet the two required conditions stated above insuring that the main dominant noise source at low frequency is the sensor itself. The equivalent magnetic noise level at $1 \mathrm{~Hz}$ strongly depends upon the excitation parameters and lowest level is reached only for an appropriate couple of dc and ac excitation current values. Fig. 4 shows the behavior of the equivalent magnetic noise level at $1 \mathrm{~Hz}$ regarding excitation parameters for sample $R 100$. Corresponding voltage sensitivity (in V/T) is also given. For each dc bias current, the noise level decreases with the increased excitation current amplitude until it reaches a minimum value, and then start to increase again. Moreover, we observed that the minimum of noise decrease and shift to the right (higher ac

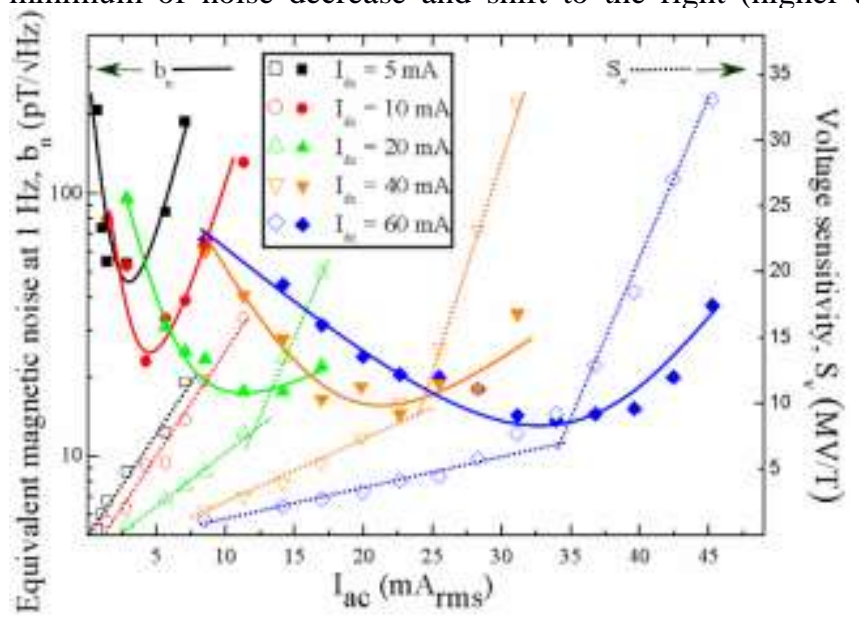

Fig. 4. Behavior of the $R 100$ sample in terms of equivalent magnetic noise and voltage sensitivity for different bias and amplitude current values, $I_{a c}, I_{d c}$, respectively. The solid and dashed lines, which correspond, respectively, to the equivalent magnetic noise at $1 \mathrm{~Hz}$ and the voltage sensitivity, are just a guide for the eyes. current amplitude) for higher dc currents. Finally, Table I summarizes the lowest equivalent magnetic noise level at $1 \mathrm{~Hz}$ obtained for the three considered samples for several dc bias current values.

TABLE I. EQUIVALENT MAGNETIC NOISE LEVEL AT $1 \mathrm{~Hz}$ COMPUTED (TH.) FROM (1) AND EXPERIMENTALLY MEASURED (MEAS.) FOR THE THREE CONSIDERED GMI WIRES CONSIDERING SEVERAL DC BIAS CURRENT VALUES.

\begin{tabular}{|c|c|c|c|c|c|c|}
\hline \multirow{2}{*}{$\begin{array}{c}\boldsymbol{I}_{\boldsymbol{d}} \\
(\mathbf{m A})\end{array}$} & \multicolumn{3}{|c|}{ Equivalent magnetic noise level at $\mathbf{H z}(\mathbf{p T} / \sqrt{\mathbf{H z})}$} \\
\cline { 2 - 7 } & \multicolumn{2}{|c|}{ Sample R80 } & \multicolumn{2}{c|}{ Sample R100 } & \multicolumn{2}{c|}{ Sample R120 } \\
\cline { 2 - 7 } & Th. & Meas. & Th. & Meas. & Th. & Meas. \\
\hline 5 & 34 & 33 & 38 & 54 & 63 & 81 \\
\hline 10 & 30 & 49 & 20 & 23 & 16 & 24 \\
\hline 20 & 20 & 18.8 & 16 & 17.7 & & 14 \\
\hline 40 & 23 & 19 & & 14.5 & & 14 \\
\hline 60 & & 18 & & 13.7 & & 13.5 \\
\hline
\end{tabular}

As expected from (1), the measured magnetic noise decreases when the GMI wire diameter increases, excepted when $I_{d c}$ is equal to $5 \mathrm{~mA}$, for which, an opposite phenomenon occurs. This can be explained by material inhomogeneity uncompensated for low DC current value. For the sample R120, corresponding to the biggest diameter, a noise level of $13,5 \mathrm{pT} / \sqrt{\mathrm{Hz}}$ at $1 \mathrm{~Hz}$ and $650 \mathrm{fT} / \sqrt{\mathrm{Hz}}$ in white noise region has been reached. In addition, we have demonstrated that the model is coherent with the wire diameter dependence, opening doors for material improvements.

\section{REFERENCES}

[1] M. Knobel, M. Vasquez, and L. Krauss, "Giant magnetoimpedance," Handbook of Magnetic Materials, vol. 15, pp. 1-92, Dec. 2003.

[2] M. Phan and H. Peng, "Giant magnetoimpedance materials: Fundamentals and applications," Progress in Materials Sciences, vol. 53, no. 2, pp. 323420, Feb. 2008

[3] B. Dufay, S. Saez, C. Dolabdjian, D. Seddaoui, A. Yelon, and D. Ménard, "Improved GMI sensors using strongly-coupled thin pick-up coil," Sensors Letters, vol. 7, no. 3, pp. 334-420, 2009.

[4] E.Portalier, Ph.D Thesis, "Etude du bruit excédentaire, en 1/f, à basse fréquence dans les magnétomètres basé sur l'effet Magnéto-impédant Géant (MIG), " CAEN Université de Caen Normandie (2016).

[5] C. Dolabdjian, B. Dufay, S. Saez, A. Yelon, and D. Ménard, "Is low frequency excess noise of GMI induced by magnetization fluctuations?" Key Engineering Materials, vol. 605, pp. 437-440, 2014.

[6] E. Portalier, B. Dufay, S. Saez, and C. Dolabdjian, D. Seddaoui, D. Ménard, and A. Yelon, "Evaluating of the imaginary part of the magnetic susceptibility, $\chi^{\prime \prime}$, and application to the estimation of the low frequency, 1/f, excess noise in GMI sensors," IEEE Trans on Mag, in press.

[7] M. Hagiwara and A. Inoue, "Rapidly Solidified Alloys: Processes, Structures, Properties, Applications", edited by H. H. Liebermann (Marcel Dekker, New York, 1993), p. 139.

[8] H. Chiriac, T. A. Ovari, and Gh. Pop, "Internal stress distribution in glasscovered amorphous magnetic wires," Phys. Rev. B, Vol. 52, pp. 10 104- 10 113, 1995.

[9] M. Phan, H. Peng, "Giant magnetoimpedance materials: Fundamentals and applications" Prog. in Mat. Sci., Vol. 53, pp.323-420, 2007.

[10] P.T. Squire, D. Atkinson, M.R.J. Gibbs, S. Atalay, "Amorphous wires and their applications”, J. Magn. Magn. Mater., Vol. 132, pp. 10-21, 1994.

[11] S. Corodeanu, H. Chiriac, N. Lupu, and T.-A. Óvári, "Magnetic characterization of submicron wires and nanowires using digital integration techniques," IEEE Trans. Magn., Vol. 47, No. 10, 2011.

[12] G. Bertotti, "General Properties of Power Losses in Soft Ferromagnetic Materials," IEEE Transactions on Magnetics, vol. 24, no. I, 1988.

[13] B. Dufay, S. Saez, C. P. Dolabdjian, A. Yelon, and D. Ménard, "Impact of Electronic Conditioning on the Noise Performance of a Two-Port Network Giant MagnetoImpedance Magnetometer," IEEE Sensors Journal, vol. 11, no. 6, pp. 1317-1324, 2011. 